\title{
A Perda de um(a) Filho(a) Jovem no Romance Paula, de Isabel Allende
}

The Loss of a Child (Young Adult): a Psychoanalytic reading Based on Isabel Allende's Novel, Paula

La Pérdida de un(a) Hijo(a) Adulto-Joven: Una Lectura Psicoanalítica a partir de La Novela Paula, de Isabel Allende

\section{Elenice Cazanatto \& \\ Margareth Kuhn Martta}

Universidade Federal do

Rio Grande do Sul

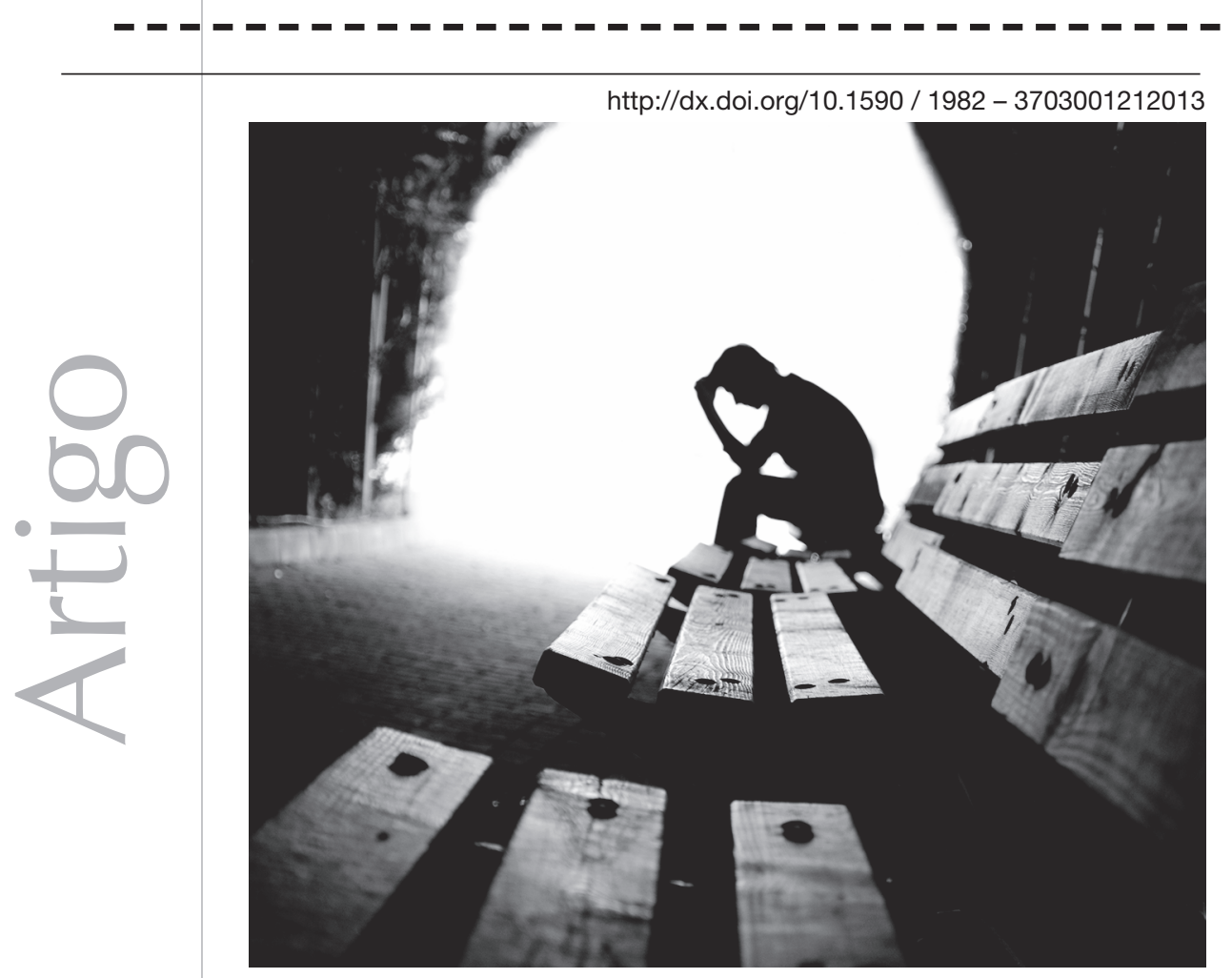


Resumo: $\mathrm{O}$ adoecimento e a perda de um filho são situações não naturalmente esperadas na perspectiva do ciclo vital, provocando uma ruptura na vida dos pais, despertando sentimentos intensos e muito sofrimento. No romance autobiográfico Paula, a autora Isabel Allende escreve para a filha que estava internada na UTI de um hospital, há alguns meses, com um diagnóstico pouco favorável. O presente artigo trata de uma leitura psicanalítica sobre a perda de um (a) filho (a) adulto-jovem, tomando como objeto de estudo a história desse romance. A partir da metodologia proposta por Iribarry (2003) de uma pesquisa psicanalítica, é realizada a construção de um ensaio metapsicológico. A história dessa obra aponta para a possibilidade de elaboração simbólica pela perda de um filho jovem, por meio da escrita literária, tendo em vista que, em Paula, o ato de escrever torna possível à mãe retomar a palavra, em uma tentativa de inscrever a perda real da filha em uma ordem simbólica.

Palavras-chave: Maternidade. Luto. Psicanálise. Literatura.

Abstract: The illness and loss of a child are situations not naturally expected from the perspective of life cycle, causing a disruption in the lives of parents, arousing intense feelings and lots of suffering. In the autobiographical novel Paula, author Isabel Allende writes to the daughter who was hospitalized in intensive care in a hospital, a few months ago, with a little favorable diagnosis. This article discusses a psychoanalytic reading about the loss of a young adult child, taking as object of study the story of this novel. From the methodology proposed by Iribarry (2003) of a psychoanalytic research, a construction of a metapsychological test is carried out. The story of this work points to the possibility of symbolic framing for the loss of a young child, through literary writing, considering that in Paula, the act of writing makes it possible to go back to the word, in an attempt to enlist the real loss of daughter in a symbolic order.

Keywords: Motherhood. Mourning. Psychoanalysis. Literature.

Resumen: La enfermedad y la pérdida de un hijo son situaciones no naturalmente esperadas en la perspectiva del ciclo vital, provocando una ruptura en la vida de los padres, despertando sentimientos intensos y mucho sufrimiento. En la novela autobiográfica Paula, la autora Isabel Allende escribe a la hija que estaba internada en la UCI de un hospital, desde hacía algunos meses, con un diagnóstico poco favorable. El presente artículo trata de una lectura psicoanalítica sobre la pérdida de un(a) hijo(a) adulto-joven, tomando como objeto de estudio la historia de esa novela. A partir de la metodología propuesta por Iribarry (2003) de una pesquisa psicoanalítica, es realizada la construcción de un ensayo metapsicológico. La historia de esa obra apunta hacia la posibilidad de elaboración simbólica por la pérdida de un hijo joven, por medio de la escritura literaria, teniendo en vista que, en Paula, el acto de escribir torna posible a la madre retomar la palabra, en una tentativa de inscribir la pérdida real de la hija en un orden simbólico.

Palabras clave: Maternidad. Luto. Psicoanálisis. Literatura.

Os textos literários tiveram um papel fundamental no desenvolvimento da Psicanálise, pois, por meio deles, foi possível nomear e sustentar importantes aspectos teórico-psicanalíticos. Em Freud, podemos citar o Édipo Rei de Sófocles, uma tragédia grega que serviu de inspiração para nomear e descrever o Complexo de Édipo, um conceito fundamental na teoria psicanalítica. Em Lacan, o estudo sobre o delírio paranoico de Aimée e a escrita de Joyce são algumas das muitas contribuições da Literatura para a Psicanálise. 
Talvez nisto consista o poder prodigioso da palavra escrita: permitenos preservar a memória, transformar o sofrimento em força, renascer em cada estação, como as velhas árvores que desenvolvem foIhas novas depois de cada inverno.

(Allende, 1997a, p. 23)

1 Paula foi traduzido para mais de 15 idiomas, sendo a versão portuguesa, a ser utilizada, traduzida por Laura Moutinho Nery, publicada pela editora Bertrand Brasil (Rio de Janeiro), em 1997 - $7^{a}$ edição.
A partir de Freud e Lacan, muitos foram os desdobramentos dessa relação, que resultaram em encontros e desencontros. O presente trabalho foi inspirado em autores psicanalíticos contemporâneos, que apostam na escrita literária como uma possibilidade de dizer o indizível e de aproximar o real do simbólico (Villari, 2000; Teixeira, 2005; Vegh, 2006; Radaelli, 2007). Tomando como objeto de estudo a história do romance Paula, escrito por Isabel Allende, buscou-se fazer uma leitura sobre a perda de um (a) filho (a) adulto-jovem, a partir dos aportes teóricos da Psicanálise.

Nesse romance autobiográfico, lançado no Chile em 1994, ${ }^{1}$ Isabel Allende escreve para sua filha Paula, que estava em estado de coma profundo. O objetivo da autora era escrever um caderno com histórias da família para presentear a filha, assim que ela acordasse, mas o estado de inconsciência de Paula foi se prolongando e essas anotações se transformaram em um romance. Na narrativa, Isabel Allende relata fatos de sua história pregressa, ao mesmo tempo em que descreve o que se passa durante o ano em que se dedicou aos cuidados de Paula, seus sentimentos em relação ao processo de adoecimento e a perda de sua filha.

Considera-se um estudo de relevância, pois a perda de um (a) filho (a) adulto-jovem provoca uma ruptura na vida dos pais, despertando sentimentos intensos e muito sofrimento. E, por tratar-se de uma situação não vista como natural, na perspectiva do ciclo vital, é difícil dar sentido a essa vivência, sendo que a escrita literária pode ser considerada como uma dessas possibilidades.

\section{A Psicanálise e a Literatura}

É Freud quem inaugura a relação da Psicanálise com a Literatura. (Villari, 2000; Teixeira, 2005; Vegh, 2006; Radaelli, 2007). Desde a obra A Interpretação dos Sonhos, em 1900, que marca o início da Psicanálise, Freud faz comentários sobre personagens da tragédia de Sófocles, retomando a ligação da Psicanálise com a Literatura ao longo de toda a sua obra.

Em 1907, Freud publica o texto Delírios e sonhos na 'Gradiva' de Jensen, sua primeira análise de um texto literário, realizada a partir do romance Gradiva, escrito por WiIhelm Jensen. Nesse texto, assinala que os escritores criativos são profundos observadores da mente humana e conseguem descrever aspectos ainda não acessíveis à ciência. Dessa forma, o escritor literário e o psicanalista bebem da mesma fonte e trabalham com o mesmo objeto, sendo que a diferença é o método que utilizam. O psicanalista dirige sua atenção para o inconsciente e para as suas manifestações, assim como o faz um escritor, mesmo sem ter consciência disso.

De acordo com Freud (1907[1908]/1969), existe uma ligação entre as brincadeiras da infância, as fantasias e a produção dos escritores criativos. A escrita criativa é um substituto da atividade de brincar da infância, sendo que ambas dependem da fantasia. O escritor criativo é capaz de reconhecer, em uma experiência presente, a lembrança de uma experiência anterior, geralmente infantil, a partir da qual encontra motivação para a realização de sua obra. Por isso, ao mesmo tempo em que a obra revela elementos atuais, traz consigo vestígios da lembrança antiga.

Para Freud (1907[1908]/1969), o pano de fundo de toda a criação é o princípio do prazer/desprazer e o princípio da realidade. Por meio da fantasia e da escrita criativa, é permitido ao sujeito aquilo que lhe é vergonhoso ou proibido na vida real. O escritor emprega métodos próprios que ajudam o leitor a se envolver com a obra, pois suaviza, altera e cria disfarces, a partir dos quais será possível a identificação e a revelação daquilo que há de mais íntimo em suas fantasias.

Para mostrar como os escritores criativos utilizam recursos para provocar efeitos de estranheza/familiaridade aos leitores, em 1919, Freud publica o texto $O$ estranho, um dos 
20 Prêmio Goethe foi criado em 1927, na cidade de Frankfurt. O prêmio deveria ser concedido anualmente para uma personalidade que tivesse realizações já firmadas, cujas obras fossem dignas de uma honra dedicada à memória de Goethe. (Freud, 1930/1969) mais importantes de sua obra. Nesse trabalho, desenvolve suas observações a partir do conto de Hoffmann, chamado O homem da areia, e analisa a proximidade das palavras estranho e familiar, que, em alemão, se escrevem unheimlich e heimlich.

De acordo com Pereira (2006, p. 34), nesse texto, Freud "evidencia de forma mais direta a imbricação da Literatura e da Psicanálise enquanto possibilidade de pensar a subjetividade: a Literatura não está ali como ilustração, mas sim compondo o caminho de elaboração". O efeito de estranhamento presente na ficção depende do jogo de posições em que o autor coloca o leitor. Trata-se de um caminho com torções, movimentos que se alternam e dependem da circulação de lugares. Assim como o analista ou o analisante, o escritor se deixa guiar pelos significantes partindo de detalhes e fragmentos, que podem alterar o rumo de uma escrita, ou mesmo de uma vida.

Além disso, a escrita de Freud é influenciada diretamente pela Literatura. Ele possui um estilo próprio e uma sensibilidade que o distinguem como escritor. Esse estilo próprio e a importância de sua obra renderam para Freud o Prêmio Goethe de Literatura, recebido em 1930. ${ }^{2}$

Na ocasião da entrega do prêmio, Freud pediu para que sua filha Anna o representasse e lesse um discurso, no qual salienta a importância da Literatura para o desenvolvimento do arcabouço teórico da Psicanálise.

Se Freud servia-se da Literatura para legitimar seus achados psicanalíticos, buscando simbolizações, palavras, formas imaginárias, figuras de linguagem e escansões que serviram para a edificação da teoria e da clínica psicanalítica, Lacan tem com a arte uma relação bem mais complexa. Segundo Radaelli (2007), o desenvolvimento da Psicanálise lacaniana se deu em um momento em que artistas surrealistas influentes, tais como André Brenton, o poeta Philippe Soupault e Salvador
Dalí, provocavam uma transformação na forma de pensar a arte e essas transformações influenciaram diretamente nos estudos teóricos de Lacan.

Lacan foi residente em Psiquiatria no Hospital Sainte-Anne e, em 1932, publicou a tese de doutorado intitulada A psicose paranóica em suas relações com a personalidade. Nesse trabalho, Lacan estuda os textos escritos por uma paciente internada, Aimée, que tinha agredido uma atriz a qual considerava sua perseguidora. Esses textos são incluídos em sua monografia não apenas como exemplo, curiosidade ou "arte bruta", mas sim como a direção de uma escuta clínica (LacôteDestribats, 2007).

Lacan estuda a paranóia no mesmo período em que artistas influentes, tais como Salvador Dalí, consideravam o delírio paranóico como uma atividade criativa. Por isso, esse trabalho de Lacan é influenciado diretamente pela arte contemporânea da época (Radaelli, 2007). Portanto, para Lacôte-Destribats (2007, pp. 86-87),

Lacan não fazia uma 'psicanálise' de uma obra de arte. Mas, como para Freud, ele levou a sério a própria letra dos achados poéticos de Aimée, sabendo que a escrita não é um modo de domínio da fala, mas que o estilo frequentemente leva para onde não se sabia inventar como ir.

Para Safatler (2006, citado por Radaelli, 2007, p. 44), Lacan se utilizava de duas vias para pensar a arte. A primeira delas seguia a interpretação do material estético, buscando o "desvelamento da gramática do desejo", como ocorre nos textos A carta roubada, de Edgar Alan Poe, O Balão, de Jean Genet, nas análises de Hamlet e em Despertar de Primavera, de Wedking.

A segunda via pela qual Lacan pensa a arte estrutura-se em torno da irredutibilidade do objeto estético. Segundo Radaelli (2007, p. 47), Lacan entende o conceito de arte como 
3 Para a Linguística, letras são sinais gráficos elementares a partir dos quais se representam os vocábulos de uma língua escrita. (Ferreira, 1993). Para a Psicanálise, a letra é um conceito estudado sob outra perspectiva. Costa (2008) situa a questão da letra a partir da proposta de Freud, das formações do inconsciente, dizendo que a letra traz algo da pulsão que ainda demanda por inscrição. Para Kaufmann (1996, p. 286), "se o significante se situa do lado do Simbóli$c o$, inaugurando a cadeia significante por intermédio do falo como significante-mestre, a letra, por sua vez, se encontra do lado do Real". De acordo com o autor, Lacan define a letra a partir da metáfora da paisagem, situando-a como "terra do litoral", "rasura de todo traço que esteja antes".

4 De acordo com Nasio (2007, pp. 4647), "o gozo não é o prazer, mas o estado que fica além do prazer; ou, para retomarmos os termos de Freud, ele é uma tensão, uma tensão excessiva, um máximo de tensão, ao passo que, inversamente, o prazer é um rebaixamento das tensões. Se o prazer consiste mais em não perder, o não perder nada e dispender o mínimo possível, o gozo, ao contrário, alinha-se do lado da perda e do dispêndio, do esgotamento do corpo levado ao paroxismo de seu esforço". uma possibilidade de "nomear aquilo que não se deixa ver, guardando, ao mesmo tempo, sua obscuridade que, longe de ser um campo de legitimação das noções me tapsicológicas, é um campo de reflexões sobre os modos de subjetivação". Por essa segunda via, Lacan pensa os textos escritos por James Joyce.

De acordo com Vegh (2006), ao escrever sobre Joyce, Lacan se permite fazer uma articulação entre a obra e a biografia do autor. Isso não quer dizer que ele fez um diagnóstico do autor, mas sim que, por meio dessa articulação, sustentou que "Joyce fez de sua obra uma barreira protetora ante a psicose. (...) Sua obra serviu de invólucro necessário às epifanias a que recorreu na vida e que inseriu em sua obra" (Vegh, 2006, p. 15). Dessa forma, Lacan utiliza a escrita de Joyce para retomar a teoria e, nessa postura de deixar-se interrogar pela escrita, questiona um dos pilares da teoria psicanalítica, trazendo avanços para a abordagem da psicose.

A arte de Joyce fascina Lacan, principalmente pelo modo como o autor utiliza a linguagem, construindo uma escrita enigmática. Lacan diz que Joyce cria um jogo de palavras que provoca um ponto de embaraço - real - a partir do qual é possível defrontar-se com os limites da análise, o que Ihe permitiu avançar em sua construção teórica. Lacan apresenta, dessa forma, uma nova concepção de sintoma - o sinthoma - e retira-o da condição de metáfora significante, efeito do recalque, para enraizá-lo no real, na conjunção entre letra $^{3}$ e gozo ${ }^{4}$.

Dessa forma, Radaelli (2007) lembra que, se a Psicanálise trabalha com aquilo que é estranho a nós mesmos: o inconsciente em Freud ou o real em Lacan, a análise de um texto literário deve partir do inconsciente, que não está ali para ser decifrado, é um objeto a ser constituído, formando configurações reversíveis. Nesse aspecto, o texto literário é trabalhado com vistas a buscar possibilidades de outros sentidos a serem articulados. "A análise do texto literário se apro- xima da análise psicanalítica, pois, ao invés de buscar o conteúdo recalcado, possibilita a criação de novos modos de pensar a partir de novos destinos para a pulsão." (Radaelli, 2007 , p. 16). Villari (2000) propõe que

aquilo que pode ser questionado não é o texto literário a partir da Psicanálise, mas seu inverso, a Psicanálise a partir da Literatura. Esse posicionamento acarreta um questionamento do saber da Psicanálise, buscando, através do texto literário aquilo que não alcançamos dizer enquanto psicanalistas. (p. 6)

Portanto, entende-se que, compreendendo o texto literário como uma possibilidade de dizer o indizível e de aproximar o real do simbólico, abrem-se possibilidades de aproximação entre a Psicanálise e a Literatura. A Literatura é considerada uma forma privilegiada de acesso ao conhecimento, o que requer o reconhecimento de que a Psicanálise é uma teoria sempre em falta e nos remete à leitura, privilegiando uma posição de não saber que nos orienta a buscar no texto aquilo que nos convoca à escrita. Ou seja, o texto literário é trabalhado com vistas a buscar possibilidades de outros sentidos a serem articulados.

\section{O ensaio metapsicológico}

O objetivo deste trabalho é realizar uma leitura psicanalítica sobre a perda de um (a) filho (a) adulto-jovem, considerando-se a história contada no romance Paula, de Isabel Allende. Por leitura psicanalítica, entendese a construção de uma análise argumentativa, tendo como referência a metodologia proposta por Iribarry (2003) da pesquisa psicanalítica e da construção de um ensaio metapsicológico.

Iribarry (2003) refere que a pesquisa psicanalítica não exige uma sistematização completa e exclusiva, visto que trabalha com o inconsciente e, portanto, com a impossibilidade de previsão. A pesquisa psicanalítica 
não inclui entre seus objetivos a necessidade de ser generalizadora, entendendo que os seus resultados podem ser diferentes, tornando sempre possível a produção de novos sentidos.

Outra particularidade da pesquisa psicanalítica é que ela trabalha com o significante e não com o signo. Entende-se que o signo é algo que traz um conhecimento de mundo, por exemplo: nuvens negras significam a presença de chuva; e o significante vai além da experiência vivencial, não está atrelado à experiência da consciência. Enquanto o signo marca a primazia de um significado, que se antecipa ao sujeito, um significante puro não impede uma associação com determinado significado, pois essa associação não será única e pode ser até múltipla. Por isso, o significante é diferente do signo, que está ligado necessariamente à realidade de mundo, "pois só é significante para determinado sujeito em determinada situação". (Juranville, citado por Iribarry, 2003, p. 121).

Caon (citado por Iribarry, 2003) propõe o delineamento de algumas linhas fundamentais para o entendimento metodológico de uma pesquisa psicanalítica. A primeira definição é quanto ao campo de pesquisa: o inconsciente. A segunda definição é em relação ao objeto, que se trata do enfoque ou da perspectiva a partir de uma posição ocupada pelo pesquisador psicanalítico, aos conteúdos inconscientes. Quanto ao método, a terceira linha fundamental para o entendimento da pesquisa psicanalítica trata-se do procedimento pelo qual o pesquisador se movimenta pelas vias ou perspectivas de acesso ao inconsciente.

Sendo assim, a partir do objeto de análise a história contada no romance Paula -, são utilizadas técnicas psicanalíticas - procedimentos - para a interpretação dos dados: a leitura dirigida pela escuta e a transferência do pesquisador ao texto (Iribarry, 2003); a criatividade e a associação livre do pesquisador (Martta, 2008).

Para a construção do ensaio metapsicológico, é importante ressaltar que, de acordo com
Iribarry (2003), "a forma do ensaio é irmã da Literatura. A ficção é o ponto de partida e o ponto de chegada do ensaísta. Entre os dois pontos está a experiência do mesmo" (p. 129). Sendo assim, o sujeito não se retira de cena, mesmo que o objeto da experiência exija uma evidência fundamental. Ele mescla sempre a leitura subjetiva da experiência com a objetividade. "O ensaio reúne o território da irracionalidade artística com o de uma ciência organizada para a produção de conhecimento" (p. 130).

Iribarry (2003) ressalta que o ensaio traz à tona a criatividade e a sensibilidade do escritor, que deixa falar seu próprio inconsciente e é capaz de perceber pulsões ocultas no íntimo das coisas e pessoas. Nesse aspecto, pode-se dizer que a ficção é audaciosa, porém ela deve renunciar ao princípio do prazer: "toda a ficção deverá ser corrigida pelo diálogo com a alteridade. E alteridade é princípio de realidade" (p. 130)

Por isso, quando se constrói um ensaio metapsicológico, deve-se levar em conta que se trata de um texto provisório sobre os resultados da investigação. Após a apreciação do público, as colocações deverão suscitar uma série de outras ideias e modificações, pois sempre haverá a possibilidade de outras leituras e de novos sentidos. É por essa via que segue a construção deste trabalho.

\section{A ficção do si mesmo, a repetição e a escrita: tentativas de elaboração simbólica pela perda de um (a) filho (a) adulto-jovem no romance Paula, de Isabel Allende}

De acordo com Ferreira (1993), o romance é uma "descrição mais ou menos longa das ações e sentimentos de personagens fictícios, numa transposição da vida para um plano artístico". Trata-se de uma "descrição ou enredo exagerado ou fantasioso" (p. 485). Autobiográfico, por sua vez, refere-se à "vida de um indivíduo escrita por ele mesmo" (p. 56).

No romance autobiográfico Paula, Isabel Allende escreve sobre o processo da escrita e 
a possibilidade de falar de si mesma por meio de seus livros:

Minha vida se faz ao ser contada e minha memória se fixa com a escrita; o que não ponho em palavras, no papel, o tempo apaga. (...) A escrita é uma longa introspecção, é uma viagem às cavernas mais escuras da consciência, uma lenta meditação. Escrevo tateando o silêncio e pelo caminho descubro partículas de verdade, cristaizinhos que cabem na palma da mão e justificam minha passagem por este mundo. (Allende, 1997b, pp. 1617)

No decorrer da narrativa, percebe-se que a autora faz uma construção da própria história e da história de sua filha, resgatando a origem de seus antepassados. De acordo com Costa (2008), a necessidade que todos têm de contar-se resulta na construção de uma ficção do si mesmo. Essa construção ficcional extrapola o registro imaginário, pois acontece por meio da fantasia, permitindo a leitura do real. À medida que o desejo se inscreve, o sujeito estará submetido às leis do simbólico e, consequentemente, inscrito na linguagem.

Segundo Costa (2008), o ato de contar-se se constitui em um paradoxo de difícil resolução, pois precisamos ser, ao mesmo tempo, o contador e o contado, sujeitos e objetos da linguagem. Para tanto, diz a autora, é preciso estar dentro e fora do argumento que se produz: "Fora, porque os humanos precisam tratar a fala como objeto de troca, produzindo certa mestria sobre ela. Dentro, porque toda a produção lida necessariamente com um representante do sujeito, sem que o mesmo saiba." (Costa, 2008, p. 17). A partir desse ato, o sujeito estabelece tanto uma identificação quanto uma diferença em relação ao outro, além de ser preciso levar em conta a ordem geracional, visto que sempre estará inserido em uma filiação, a partir da qual poderá construir a sua versão da história.

Escrever também é uma forma de contar-se, de fazer uma construção ficcional do si mes- mo. Pode-se dizer que, em Paula, a obra literária se refere à autora de uma forma muito particular, podendo ser considerada como uma construção ficcional que ela faz da própria história. Mas, é importante ressaltar que essa construção do si mesmo tem sempre o estatuto de ficção e, para a Psicanálise, a ficção não tem exatamente um estatuto de conceito, visto que o fundamento conceitual é diferente de outras disciplinas e liga-se ao efeito que produz.

Nesse aspecto, diz Gagnebin (2006): antes de teórico, o psicanalista é o relator do testemunho, ou seja, aquele que consegue ouvir a narração do outro e que aceita que suas palavras levem adiante, como em um revezamento, a história do outro. É somente a transmissão simbólica que possibilita não repetir infinitamente, mas ousar esboçar outra história, a inventar o presente.

De acordo com o autor, "não é a sensação em si (...) que determina o processo da escrita verdadeira, mas sim a elaboração dessa sensação (...), a transformação, pelo trabalho da criação artística, da sensação em linguagem, da sensação em sentido". (Gagnebin, 2006, p. 154). Isabel escreve:

Minha infância foi um tempo de medos silenciados. (...) Sempre me senti diferente, desde que me entendo por gente vivi marginalizada; não pertencia realmente à minha família, ao meio social, a um grupo. Suponho que desse sentimento de solidão nascem as perguntas que me impelem a escrever, na busca de respostas se fazem os livros". (Allende, 1997b, pp. 72-73)

Ao contar a sua história e a história de seus antepassados para que a filha, que estava em coma e com a possibilidade de ter sofrido danos neurológicos irreversíveis, pudesse ler quando acordasse, pode-se pensar que, para além daquilo que está dito, a autora escreve para que a filha possa de alguma forma continuar existindo, fazendo parte de sua vida. Assim, ela se refere: 
Até agora não compartilhei meu passado, é meu último jardim, onde nem mesmo o amante mais íntimo se insinuou. Fique com ele, Paula, talvez Ihe sirva para alguma coisa, porque creio que o seu passado não existe mais, que você o perdeu nesse longo sono, e não se pode viver sem lembranças. (Allende, 1997b, p. 36)

Pode-se pensar que, para a autora, a escrita literária se tornou uma forma de continuar a comunicar-se com a filha que estava em coma profundo: "Escute, Paula, vou contar uma história para que você não se sinta tão perdida quando acordar" (Allende, 1997b, p. 9); "não sei como atingi-la, chamo-a e não me ouve, por isso escrevo para você" (Allende, 1997b, p. 106).

O exercício da escrita configura a possibilidade de enfrentar, por meio da atividade intelectual, a ameaça do esquecimento, do silêncio e da morte. Enquanto a transmissão oral viva é frágil e efêmera, a escrita permite a conservação, por meio de uma inscrição que talvez perdure por mais tempo, mas que desenha o vulto da ausência, visto que "nem a presença viva nem a fixação pela escritura conseguem assegurar a imortalidade; ambas, aliás, nem mesmo garantem a certeza da duração, apenas testemunham o esplendor e a fragilidade da existência, e do esforço de dizê-la" (Gagnebin, 2006, p. 11).

$\mathrm{O}$ ato de escrever pode ser considerado como uma tentativa de perpetuar a lembrança de uma história, de não esquecer dos mortos, dos vencidos, e de não calar suas vozes. Mas, ao mesmo tempo em que luta contra as forças do esquecimento, a escrita corre o risco de petrificar o presente, na medida em que para escrever é necessário codificar e fixar, transformando a plasticidade em rigidez, afirmando e confirmando sua ausência e prenunciando a sua morte (Gagnebin, 2006).

No decorrer da narrativa, Isabel afirma que é comum ela escrever quando perde pessoas que foram importantes em sua vida, ou per- cebe a possibilidade de perdê-las. Sobre a morte da avó, Isabel diz que "escrevia mensagens em pedaços de papel, dobrava-os com cuidado e os prendia com um alfinete no tecido grosso para que ela os encontrasse e soubesse que eu não a esquecera" (Allende, 1997b, pp. 40-41).

Isabel também se mostra identificada com o avô. Ela lembra que ele era um grande contador de histórias, dotado de humor negro, capaz de contar cenas horripilantes soltando boas gargalhadas. Os casos acumulados durante tantos anos, os principais acontecimentos históricos do século, as extravagâncias da família, os infinitos conhecimentos que adquiriu em suas leituras proporcionaram à neta material suficiente para escrever muitos livros. Quando o avô adoeceu, ela estava no exílio e, por isso, resolveu escrever uma carta para despedir-se dele:

Hoje são 8 de janeiro de 1992. Neste mesmo dia, há onze anos, comecei em Caracas uma carta para me despedir de meu avô, que agonizava com um século de luta nas costas. (...) Pouco depois o velho morreu, mas o texto tinha tomado conta de mim e não pude parar (...). No final daquele ano tinham-se acumulado quinhentas páginas numa sacola de lona e compreendi que aquilo não era mais uma carta; então anunciei timidamente à família que tinha escrito um livro. (...) Este livro me salvou a vida. (Allende, 1997b, pp. 16-17)

Isabel refere que, em todos os anos, nessa mesma data, começa a escrever seus livros. Essa é também a data em que ela iniciou o livro Paula.

Sendo assim, é interessante considerar o conceito de rastro, que é trabalhado por Gagnebin (2006). Trata-se de um conceito obscuro que procura manter juntas a presença do ausente e a ausência da presença. A escrita é considerada um rastro privilegiado que os homens deixam de si mesmos, sendo por muito tempo considerada o rastro 
mais duradouro, capaz de sobreviver à morte de seu autor e deixar sua mensagem. "O rastro inscreve a lembrança de uma presença que não existe mais e que sempre corre o risco de se apagar definitivamente. Sua fragilidade essencial e intrínseca contraria o desejo de plenitude, de presença e de substancialidade." (p. 44).

Em relação ao romance Paula, pode-se pensar que, decifrando os rastros e juntando os restos de sua história, a autora busca manter presente aqueles a quem perdeu, ao mesmo tempo em que tenta lidar com a sua ausência - seja a ausência física, seja a psíquica. Isabel se refere à morte dos avós, ao desaparecimento do pai, ao desaparecimento do irmão, à separação do esposo, às constantes mudanças de país, ao exílio durante o Golpe Militar no Chile, à perda dos sogros, às perdas materiais, dentre outras perdas que teve durante a vida.

Para justificar o desaparecimento do pai, Isabel escreve que criou razões mórbidas e fantasiosas:

Na infância imaginei-o como um criminoso e mais tarde, quando soube de perversões sexuais, atribuí todas a ele, mas parece que nada tão romanesco ornamenta seu passado; era apenas uma alma covarde; um dia se viu acossado pelas próprias mentiras, perdeu o controle da situação e escapuliu. (Allende, 1997b, pp. 26-27)

A fantasia é um mecanismo utilizado para suportar as situações de perdas. Para Freud (citado por Nasio, 2007, p. 9), "a fantasia é o reino intermediário que se inseriu entre a vida segundo o princípio de prazer e a vida segundo o princípio de realidade". De acordo com Nasio (2007, p. 10), a fantasia é um romance de bolso que podemos abrir em qualquer lugar e que irá interferir na realidade imediata. Trata-se, diz o autor, de "um teatro mental catártico que encena a satisfação do desejo e descarrega sua tensão". Isabel refere que, em seu terceiro livro, Eva Luna, a personagem principal da trama diz: "Quando escrevo, conto a vida como eu gostaria que ela fosse, como um romance." (Allende, 1997b, p. 360).

Enquanto narra a história do romance Paula, percebe-se que Isabel estabelece uma relação muito próxima entre as situações de perdas e o processo da escrita literária - que pode ser considerada uma mistura de ficção, fantasia e realidade -, como forma de lidar com as situações que vivencia. "O tempo solitário com a escrita é o meu tempo mágico, a hora das feitiçarias, o único tempo capaz de me salvar quando tudo em volta ameaça ruir" (Allende, 1997b, p. 430). Em outro trecho, ela refere: "A partir das primeiras linhas, outros desígnios se apoderaram da carta, afastando-me da história incerta da família para explorar o mundo seguro da ficção" (Allende, 1997b, p. 382).

Isabel cita não só as perdas, devido à morte de pessoas queridas, como também as mudanças, perdas materiais e separações. "Entre furtos, exílio, divórcio e viagens houve tantas perdas, que agora basta que eu compre alguma coisa, para ir me despedindo dela, porque sei quão pouco irá durar em minhas mãos" (Allende, 1997b, p. 163).

Para Radaelli (2007), a escrita literária permite a construção de um litoral, no limite entre o saber e a verdade do inconsciente, trazendo consigo o selo da ficção, que é a verdade do sujeito. Pode-se levantar a hipótese de que, ao rememorar essas experiências dolorosas e contar por meio da escrita literária, Isabel tenta suportar a dor e a angústia diante da possibilidade de perda da filha.

Para Nasio (1997, p. 57), quando existe a ameaça de perder alguém que amamos surge a angústia. A angústia é uma reação à ameaça da perda de um objeto amado, que protege o eu da ruptura e do trauma da perda. Quando alguém está condenado à morte, como no caso de uma doença grave, o eu se prepara para a separação: "É verdade que estou me distanciando, a dor é um caminho solitário" (Allende, 1997b, p. 157). 
No decorrer da narrativa, Isabel se refere à dor por perceber que o mais provável é que a filha não acorde do coma profundo: "Jogome nestas páginas numa tentativa irracional de vencer meu terror, parece que dando forma a esta devastação poderei ajudar você a me ajudar, o meticuloso exercício da escrita pode ser a nossa salvação" (Allende, 1997b, p. 17). Em outro momento, escreve: "Minha avó escrevia nos seus cadernos para reter momentos fugidios e tapear a memória fraca. Eu tento distrair a morte" (Allende, 1997b, p. 230).

Nasio (1997) ressalta que a dor é uma defesa contra a loucura e o naufrágio do eu. A dor é o real que invade, e a simbolização só será possível mais tarde, quando se iniciar o trabalho de luto. "Em si, a dor não tem nenhum valor nem significado. Ela está ali, feita de carne ou de pedra, e, no entanto, para acalmá-la, temos que tomá-la como a expressão de outra coisa, destacá-la do Real, transformando-a em símbolo" (p. 19) . Isabel escreve:

Decidi não procurar alívio nos remédios; este é um caminho que devo percorrer sangrando. (...) A estranha doença de minha filha talvez seja como aquele parto: preciso apertar os dentes e resistir com coragem, sabendo que este tormento não será eterno, que um dia ele termina. Como? Só pode ser com a morte (...) Deixo a dor me invadir sem lhe opor mais qualquer resistência. (Allende, 1997b, p. 409,450$)$

Segundo Nasio (1997), não é a ausência do outro que causa a dor, mas o vazio com o qual se depara o nosso desejo, que fica privado de seu objeto excitante. No caso de uma perda, a dor remete à necessidade de uma separação, causando uma transformação, principalmente pela ideia de que será preciso reconstruir a vida sem o outro. Para o autor, quando se perde alguém que se ama, a conexão e a textura de uma fantasia indispensável à nossa estrutura deixam de existir. Perdemos aquele que sustenta o nosso desejo, objeto das projeções imaginárias de nossas imagens interiores e o ritmo da força do desejo. Por isso, deparamo-nos com uma tensão interna que é extrema, e isso é a dor que aparece no limite do sofrimento e da loucura.

A dor enquanto afeto "é um estremecimento final que comprova a vida e o nosso poder de nos recuperarmos" (Nasio, 1997, p. 20). Por isso, a dor nem sempre é patológica e pode ser entendida como uma passagem que leva a atravessar algum limiar. "Não se morre de dor", ao contrário, "enquanto há dor, também temos as forças disponíveis para combatê-la e continuar a viver" (pp. 19-20). Isabel refere: "A dor é inevitável na nossa passagem pela vida, mas dizem que pode ser quase sempre suportável se não houver resistência e se não acrescentarmos a ela o medo e a angústia" (Allende, 1997b, p. 263).

Quando existe a ameaça de morte a dor do luto começa a ser nomeada antes de aparecer, permitindo que o trabalho de luto se inicie antes da morte da pessoa amada, o que significa uma dor integrada ao eu, embora ainda insuportável (Nasio, 1997).

Isabel consegue, por meio da escrita, referirse à iminência da perda da filha, entendendo que ela não é mais a destinatária daquilo que está sendo escrito: "Já não escrevo para que minha filha não se sinta tão perdida quando acordar, porque ela não acordará. Estas páginas não têm destinatário, Paula nunca poderá lê-las" (Allende, 1997b, p. 285). Em outro momento, a autora afirma: "Sua única saída é a morte, filha, agora me atrevo a pensar isto, a dizê-lo para você, a escrevê-lo no meu caderno amarelo" (Allende, 1997b, p. 451).

Levanta-se a hipótese que Isabel escreve sobre a perda da filha buscando uma forma de lidar com esse evento traumático. Para Freud (1920/1969), a repetição de uma experiência traumática constitui-se em uma tentativa de elaboração dessa experiência. Para Lacan, o traumático de Freud é o real, 
que não cessa de se inscrever. Nessa perspectiva, pode-se considerar que, na construção ficcional dessa obra literária, existe um processo de rememoração das perdas eventos traumáticos - por meio da escrita, em uma tentativa de inscrição simbólica para dar conta desse real que não cessa. A partir da escrita literária, Isabel passa a assumir uma posição ativa diante das experiências de perdas vividas passivamente.

De acordo com Gagnebin (2006), uma memória traumática impossibilita à linguagem cotidiana e à narração tradicional assimilarem o choque, o trauma, visto que este, por definição, fere, separa, corta ao sujeito esse acesso ao simbólico, em particular, à linguagem. "O trauma é a ferida aberta na alma, ou no corpo, por acontecimentos violentos, recalcados ou não, mas que não conseguem ser elaborados simbolicamente, em particular sob a forma de palavra, pelo sujeito" (Gagnebin, 2006, p. 110). Como refere Isabel: "É muito difícil escrever estas páginas, Paula, percorrer de novo as etapas desta viagem dolorosa, avivar os detalhes, imaginar como seria se você tivesse caído em melhores mãos" (Allende, 1997b, p. 34).

Segundo Gagnebin (2006), a rememoração não implica somente repetir aquilo que se lembra, mas abrir-se "aos brancos, aos buracos, ao esquecido e ao recalcado, para dizer, com hesitações, solavancos, incompletude, aquilo que ainda não teve direito nem à lembrança nem às palavras" (p. 55). A rememoração implica uma atenção precisa ao presente, em particular às estranhas ressurgências do passado no presente, visto que "não se trata somente de não se esquecer do passado, mas também de agir sobre o presente. A fidelidade ao passado, não sendo um fim em si, visa à transformação do presente" (p. 55). Assim expressa Allende (1997b):

Escrever me faz bem, apesar de ser às vezes penoso, porque cada palavra é como uma queimadura. Estas páginas são uma viagem irreversível por um longo túnel, não enxergo a saída, mas sei que deve haver alguma; im- possível voltar atrás, tudo é questão de continuar avançando passo a passo, até o final. Escrevo procurando um sinal, esperando que Paula rompa seu implacável silêncio e me responda sem voz nestas folhas amarelas, ou talvez o faço somente para superar o espanto e fixar estas imagens fugazes antes que elas caiam no esquecimento. (p. 330)

Durante a construção do romance, percebe-se que Isabel estabelece certa continuidade em relação aos fatos passados e atuais, que estão relacionados a experiências de perdas reais e simbólicas. Por meio da escrita, a autora repete suas histórias de perdas, rememorando-as: "As recordações de minha infância são dramáticas, como as de todo mundo, suponho, porque as coisas banais caem no esquecimento, mas isso também pode se dever à minha inclinação para a tragédia" (Allende, 1997b, pp. 76-77).

Segundo Nasio (1997), a cada perda, o indivíduo pode reviver suas perdas antigas. $\mathrm{O}$ autor refere-se a Freud e a Lacan e desenvolve a ideia de que o luto é um "buraco no Real", opera como o núcleo central de um turbilhão de energia, como um abismo em cujas bordas o sistema simbólico gravitaria em um movimento centrípeto. Nasio (1997) ressalta que não se perde uma pessoa quando ela morre, mas após um longo processo de elaboração, que implica um laborioso processo de recalcamentos, diversos retornos do recalcado, sintomas e flutuações na vida do sujeito.

Para Mannoni (1995), a elaboração do luto pela morte de um filho é quase impossivel, visto que o adulto jamais se recupera de uma experiência como essa. "Ele se vê amputado de uma parte de si mesmo, projetada na sua descendência. Vê-se de repente muito velho, como que fora do tempo, e que não pode mais sonhar com o futuro através de sua descendência" (p. 93). A autora ressalta que Freud perdeu sua filha Sophie e seu neto Heinele, filho mais novo de Sophia. Nesse período, o autor trocou muitas cartas com Jones, partilhando sua dor. 
5 Para Kehl (1998), na contemporaneidade as mulheres buscam um discurso próprio que vai além da maternidade e do casamento. Segundo a autora, o que faz a diferença, tanto na feminilidade quanto na masculinidade, não é ter ou não ter o pênis, mas ter ou não ter o "falo da fala", o Verbo.
Mannoni (1995) se refere a uma passagem em que Freud observa que "a ferida narcísica" aberta nessas ocasiões é irreparável, atingindo o sujeito de forma tão radical que ele não tem palavras para traduzir o que sente. "A morte do filho despedaça o pai" (p. 94).

Zygouris (1995, p. 100) em seu artigo Uma palavra que falta, diz que não existe, ou ainda não foi criada uma palavra para nomear a mãe ou o pai que perdem seu filho. A autora ressalta que "não faz parte da ordem natural das coisas a criança morrer antes daquele e daquela de quem ganhou a vida e que terão de sobreviver. Quando a ordem da natureza se inverte, não há palavras".

Segundo Zygouris (1995), a perda de um ente querido é sempre marcada por um nome, que designa a relação com o falecido e que coloca o indivíduo em uma posição passiva diante daquele que morreu. Por exemplo, a morte de um esposo deixa a mulher viúva, a morte dos pais deixa os filhos órfãos. Porém, como poderíamos chamar um pai e uma mãe que perdem seu filho?

A ausência de um nome equivalente ao de um órfão, do lado parental, não permite a este pai ou a mãe ocupar uma posição passiva de vivo perante a morte de seu filho. Penso, justamente, não existir posição passiva de vivo ante tal acontecimento. É essa a "coisa" que falta. (...) Podem, caso tenham as palavras, e essas não faltam, queixar-se, gritar acusar, esquecer, fazer outros filhos, mas nenhuma palavra significando seu luto e o direito a ele virá inocentá-los, seja perante si mesmos, seja perante os demais. (Zygouris, 1995, p. 101)

Nessa perspectiva, é importante considerar que, se para Freud (1924/1969), o filho é o substituto simbólico para o falo e, se para Kehl (1998), o falo é a fala ${ }^{5}$, na perda de um filho a mãe se vê diante do real da castração, em todos esses sentidos. Talvez por isso a perda de um filho seja tão traumática para a mãe: ao mesmo tempo em que perde o filho/falo, fica privada de palavras que pos- sam nomear essa perda, o que a remete também à castração da fala. Por isso, pode-se pensar que, por meio da construção da própria história, pela escrita literária, e do mecanismo da repetição, Isabel busca uma saída para enfrentar a dor pela iminência da perda da filha.

E, nesse aspecto, levanta-se a hipótese de que a escrita literária pode se constituir em uma tentativa de elaboração simbólica pela perda de um filho, visto que, por meio dela, torna-se possível retomar a palavra, em uma tentativa de inscrever a perda em uma ordem simbólica. Como refere Isabel Allende:

O processo alegre de gerar um filho, a paciência na gestação, a força para trazê-lo à vida e o sentimento de profundo assombro em que isso culmina só podem ser comparado à criação de um livro. Os filhos, como os livros, são viagens ao nosso interior, nas quais o corpo, a mente e a alma invertem seus rumos, regressando ao próprio centro da vida. (Allende, 1997b, p. 321)

\section{Considerações finais}

Considerando-se a proposta de realizar uma leitura psicanalítica sobre a perda de um (a) filho (a) adulto-jovem, a partir do romance Paula, de Isabel Allende, é possível pensar que a história dessa obra aponta para a escrita literária como uma possibilidade de se constituir em uma das saídas possíveis diante da dor pela perda de um filho. Diz-se dor porque, em uma primeiro momento, é preciso lidar com a dor, com a ruptura provocada pela perda, para que mais tarde o trabalho de luto se inicie.

Na construção da história do romance, existem dois momentos distintos: o primeiro, em que a mãe escreve para que a filha possa ler quando acordar e que pode ser entendido como um intenso investimento afetivo, provocado pela iminência da perda; e o segundo momento, em que a mãe percebe que a filha não lerá o livro, mas, mesmo 
assim, continua a escrever, entendendo-se que, a partir de então, a dor da perda começa a ser simbolizada.

Ao ler a obra, é como se estivéssemos acompanhando o desenrolar de um processo terapêutico, com suas angústias, elaborações e a tomada de novos rumos. Nasio (1997), ao discorrer sobre o lugar ocupado por aqueles que se propõem a escutar a dor do outro - e nesse caso em específico, pode-se pensar na dor de uma mãe diante da perda de um filho -, refere que a dor se irradia para quem escuta.

Por isso, em um primeiro momento, há que se colocar no lugar daquele que, somente por sua presença, mesmo que silenciosa, poderá dissipar o sofrimento e receber suas irradiações. É desse lugar que a impregnação aquém do que é dito verbalmente pode inspirar as palavras adequadas para expressar a dor e por fim acalmá-la.

\section{Elenice Cazanatto}

Especialista em Psicologia Clínica pela Universidade Caxias do Sul - RS. Brasil

E-mail: nicecazanatto@yahoo.com.br

\section{Margareth Kuhn Martta}

Doutora em Educação pela Universidade Federal do Rio Grande do Sul e Docente da

Universidade Caxias do Sul - RS. Brasil.

E-mail: zmmartta@uol.com.br

Endereço para envio de correspondência:

Rua Júlio de Castilhos, no 940, sala 206, centro. CEP: 95180-000. Farroupilha, RS. Brasil

Recebido 10/04/2013, Aprovado 12/12/2013. 


\section{Referências}

Allende, I. (1997a). Cartas a Paula (E. Gaidano, trad.). Rio de Janeiro: Bertrand Brasil.

Allende, I. (1997b). Paula (7a. ed., I. Moutinho, trad.). Rio de Janeiro: Bertrand Brasil.

Costa, A. M. M. (2008). Relações entre letra e escrita nas produções em Psicanálise. Estilos da Clínica, 13(24), 40-53. Recuperado de http://pepsic.bvsalud.org/scielo.php?pid=S1415 $-71282008000100004 \&$ script $=$ sci_arttext.

Ferreira, A. B. H. (1993). Minidicionário da língua portuguesa (3a. ed.). Rio de Janeiro: Nova Fronteira.

Freud, S. (1969). A dissolução do complexo de Édipo (J. Riviere, trad.). In Edição Standard Brasileira das Obras Completas de Sigmund Freud (Vol. 19, pp. 191-199). Rio de Janeiro: Imago. (Trabalho original publicado em 1924).

Freud, S. (1969). A interpretação dos sonhos (W. I. Oliveira, trad.). In Edição Standard Brasileira das Obras Completas de Sigmund Freud (Vol. 04). Rio de Janeiro: Imago. (Trabalho original publicado em 1900).

Freud, S. (1969). Além do princípio do prazer (J. Strachey, trad.). In Edição Standard Brasileira das Obras Completas de Sigmund Freud (Vol. 18, pp. 13-75). Rio de Janeiro, RJ: Imago. (Trabalho original publicado em 1920).

Freud, S. (1969). Delírios e sonhos na Gradiva de Jensen (J. Strachey, trad.). In Edição Standard Brasileira das Obras Completas de Sigmund Freud (Vol. 9, pp. 15-79). Rio de Janeiro: Imago. (Trabalho original publicado em 1907[1906]).

Freud, S. (1969). Escritores criativos e devaneio (I. F. Frant Duff, trad.). In Edição Standard Brasileira das Obras Completas de Sigmund Freud (Vol. 9, pp. 133-143). Rio de Janeiro: Imago. (Trabalho original publicado em 1908[1907]).

Freud, S. (1969). O estranho (A. Strachey, trad.). In Edição Standard Brasileira das Obras Completas de Sigmund Freud (Vol. 17, pp. 235273). Rio de Janeiro: Imago. (Trabalho original publicado em 1919).

Freud, S. (1969). O Prêmio Goethe (A. Richards, trad.). In Edição Standard Brasileira das Obras Completas de Sigmund Freud (Vol. 21, pp. 211-219). Rio de Janeiro: Imago. (Trabalho original publicado em 1930).
Gagnebin, J. M. (2006). Lembrar escrever esquecer. São Paulo: Ed. 34.

Iribarry, I. N. (2003). O que é pesquisa psicanalítica? Ágora, 6(1), 115-138. doi: http://dx.doi.org/10.1590/S1516-14982003000100007.

Kaufmann, P. (1996). Dicionário enciclopédico de psicanálise: o legado de Freud e Lacan (V. Ribeiro, M. L. Borges, trads.). Rio de Janeiro: Jorge Zahar Ed.

Kehl, M. R. (1998). Deslocamentos do feminino: a mulher freudiana na passagem para a modernidade. Rio de Janeiro: Imago.

Lacôte-Destribats, C. (2007). O inconsciente: uma exposição para compreender, um ensaio para refletir (M. Fleig e C.G. Viola, trads.). São Leopoldo, RS: Editora Unisinos. (Coleção Aldus 30).

Mannoni, M. (1995). O nomeável e o inominável - A última palavra da vida. Rio de Janeiro: Jorge Zahar Ed.

Martta, M. K. (2008). Psicanálise e Cinema: a subjetividade contemporânea nas fabulações da cultura. Tese de doutorado. Programa de PósGraduação em Educação, Universidade Federal do Rio Grande do Sul. Porto Alegre, Brasil.

Nasio, J. D. (1997). O livro do amor e da dor (L. Magalhães, trad.). Rio de Janeiro: Jorge Zahar Ed. (Trabalho original publicado em 1996).

Nasio, J. D. (2007). A fantasia: O prazer de ler Lacan (A. Telles e V. Ribeiro, trads.). Rio de Janeiro: Jorge Zahar Ed. (Trabalho original publicado em 2005).

Pereira, L. S. (2006). Sobre "Dom Casmurro, um narrador incerto entre o estranho e o familiar". Correio da Appoa, 13(152), 31-38.

Radaelli, J. (2007). O sujeito e a ficção da escrita - Uma articulação entre Psicanálise, Literatura e Educação. Dissertação de mestrado, Programa de Pós-Graduação Psicologia e Educação, Faculdade de Educação, Universidade de São Paulo. São Paulo, Brasil.

Teixeira, L. C. (2005). O lugar da literatura na constituição da clínica psicanalítica em Freud. Psychê, 9(16), 115-132. Recuperado de http://pepsic.bvsalud.org/scielo. php?script $=$ sci_arttext\&pid $=$ S 1415 $11382005000200008 \& \operatorname{lng}=$ pt\&nrm $=$ iso. 
Vegh, I. (2006). O despertar. Literatura e Psicanálise. Correio da Appoa, 13(152), 11-20.

Villari, R.A. (2000). Relações possíveis e impossíveis entre a psicanálise e a literatura. Psicologia Ciência e Profissão, 20(2), 2-7. doi: http://dx.doi.org/10.1590/S141498932000000200002 .
Zygouris, R. (1995). Ah! As belas lições! (C. Koltai, trad.). São Paulo: Escuta. 